\title{
Incorporation of alpha-fetoprotein(AFP) into subclassification of BCLC C stage hepatocellular carcinoma according to a 5-year survival analysis based on the SEER database
}

\author{
Nan Zhang ${ }^{1,2,3, *}$, Jiajia Gu${ }^{2, *}$, Li Yin ${ }^{1,2,3}$, Jing Wu ${ }^{2}$, Ming-yu Du ${ }^{1,2,3}$, Kai Ding ${ }^{2,3,4}$, Teng \\ Huang ${ }^{1,2,3}$, Xia He $\mathrm{He}^{1,2,3,4}$ \\ ${ }^{1}$ The Fourth Clinical School of Nanjing Medical University, Nanjing, China \\ ${ }^{2}$ Department of Radiation Oncology, Jiangsu Cancer Hospital and Jiangsu Institute of Cancer Research, Nanjing, China \\ 3 Jiangsu Key Laboratory of Molecular and Translational Cancer Research, Nanjing, China \\ ${ }^{4}$ Xuzhou Medical University, Xuzhou, China \\ "These authors contributed equally to this work
}

Correspondence to: Xia He, email: hexiabm@163.com

Keywords: AFP, hepatocellular carcinoma, BCLC, SEER

Received: March 18, 2016

Accepted: November 01, 2016

Published: November 09, 2016

\section{ABSTRACT}

Purpose: To evaluate the effect of serum alpha-fetoprotein(AFP) on prognosis of patients with hepatocellular carcinoma (HCC) and put forward a proposal to modify BCLC staging system and the recommended treatment of patients with stage $C$.

Results: AFP positive was an independent poor prognostic factor of HCC. Race, pathological grade, $T$ stage, $M$ stage were also regarded to be significant predicted factors for poorer prognosis. When combining AFP status with AJCC stage, patients with A1 disease had a worse prognosis compared with those with AO disease within each stage. Patients with A1 disease of each $\mathrm{T} / \mathrm{N}$ stage had a worse prognosis than patients with $\mathrm{AO}$ disease of the respective stage, and the prognosis of patients with A1 disease with lower $\mathrm{T}$ stages was worse or similar to that of patients with $\mathrm{AO}$ disease of higher $\mathrm{T}$ stages.

Materials and Methods: We performed a retrospective study of all patients histologically diagnosed HCC from January 1, 2004, through December 31, 2008, from the SEER database.

Conclusions: AFP can be used as a subclassification index to modify the AJCC staging system of HCC. Since BCLC stage is the most widely used staging system, we recommend routine pre-treatment AFP testing as standard of care in HCC and incorporate AFP status into the BCLC staging system to modify the recommended treatment of patients with stage $C$.

\section{INTRODUCTION}

Liver cancer is a threat to public health and a major cause of cancer-related deaths in our country and many other parts of the world, $90 \%$ of which is hepatocellular carcinoma (HCC) [1]. About 6.12 new cases and 4.52 deaths occur annually per 100,000 people in United States of America according to GLOBOCAN2012 (http:// globocan.iarc.fr/Pages/Map.aspx\#).

Successful management of cancer depends on adequate therapeutic protocols, evaluation of curative effect and prognostication based on accurate staging in clinical practice. The clinicians has identified the potential limitation of pure anatomical staging. Optimal treatment depends on the anatomical staging (i.e. traditional tumornode-metastasis (TNM) stage, the underlying liver function, and the general state of the patient [2]. To date, the classification criteria of HCC is still controversial. The TNM system, the most widely adopted standard staging system of all cancers, was considered not informative for $\mathrm{HCC}$ with regard to treatment guidance efficacy and prognosis accuracy [3]. Novel combined-staging systems using tumor and residual liver function factors have been proposed, such as the Cancer of the Italian Liver Program (CLIP) [4], the Barcelona Clinic Liver Cancer (BCLC) [5], the Japanese Intergrated Staging (JIS) [6] and the Hong 
Kong Liver Cancer [7]. Among them, the BCLC is a reference classification system of HCC in the West, which is based on randomized studies and recommend treatment modality. Nonetheless, the BCLC is still criticized for its lack of universal applicability. Kwang et al. demonstrated that the 5-year survival rate of the the population that received therapy according to the BCLC treatment algorithm was better only for the early stages $(0, \mathrm{~A})[8]$.The reason is not obvious. Taken together, a reconsideration of treatment strategies is urgent for the management of HCC.

Despite the disadvantage of low sensitivity, low specificity and limited accuracy in HCC early diagnosis, serum alpha-fetoprotein (AFP) has still been recommended as a biomarker to evaluate prognosis and monitor recurrence following treatment for $\mathrm{HCC}$ in clinical practice [9-12]. Accordingly, to address the above limitations, we intend to use AFP as a subclassification criterion to modify the BCLC stage. We used the National Cancer Institutes Surveillance, Epidemiology, and End Results (SEER) database to analyze the survival outcomes after incorporating AFP into the AJCC staging.

\section{RESULTS}

\section{Clinicopathologic characteristics of patients with A0 and A1 stage}

During the 5-year study period, 12908 records were enrolled from the SEER database, including 11999 hepatocellular carcinoma (HCC), 796 intrahepatic cholangiocarcinoma (ICC) and 113 combined HCC and ICC. Analyzing AFP level on overall survival (OS) and disease-special survival (DSS) based on different histological types by univariate analysis showed that A0 stage patients had an increased 5-year OS and DSS in HCC group (Table 1). However, similar difference hasn't been seen in other subgroups (ICC and combined). Therefore, we choose all patients with HCC to continue our study. Patient demographics and clinicopathologic features are summarized in Table 2.

Of the entire study cohort, 2660 patients were AFP negative (A0) and 9339 patients were AFP positive (A1). There were statistically significant differences in all the variables across A0 and A1 stage groups $(P<0.05)$, except sex $(p=0.232)$. Compared with the A0 group, the A1 group had less early cases (fewer grade I and II: 51\% vs $67.5 \%$ ). In addition, more patients in A0 group underwent surgery treatment (43.1\% vs $27.7 \%$ of A1 group).

\section{AFP as an independent prognostic factor in $\mathrm{HCC}$}

Multivariate analysis were performed by the Cox regression model to identify factors independently associated with overall and disease-specific mortality (Table 3). AFP positive was an independent poor prognostic factor associated with an increase in overall mortality (HR, 1.460; 95\% CI, 1.385-1.539; $P<0.001$ ) and disease-specific mortality (HR, 1.514; 95\% CI, 1.430-1.603; $P<0.001)$. Moreover, the following four factors were also regarded to be significant risk factors for poorer prognosis, including race (Black, HR 1.115, 95\% CI 1.048-1.187; Other, HR 0.822, 95\% CI 0.778-0.869), pathological grade (III-IV, HR 1.347, 95\% CI 1.2451.457), T stage (T3, HR 1.748, 95\% CI 1.653-1.848; T4, HR 1.676, 95\% CI 1.522-1.845; Tx, HR 1.780, 95\%CI 0.609-1.968), M stage (M1, HR 1.986, 95\% CI 1.8622.119; Mx, HR 2.277, 95\% CI 1.672-3.102). However, no statistical differences were observed with regards to sex $(p=0.109), N$ stage $(p=0.472)$ and T2 stage $(p=0.559)$ according to multivariate mortality analysis. The univariate log-rank test showed that the 5-year DSS was $37.65 \%$ and $19.23 \%$ in the $\mathrm{A} 0$ and $\mathrm{A} 1$ groups, respectively $(p<0.001)$ (Figure 1).

Besides, survival analysis layering for surgical treatment of patients with non-surgical treatment of T3 and T4 patients with different AFP status was conducted via standard Kaplan-Meier estimates, as is shown in Figure S1. In the surgery group, the 5-year OS of T4 with AFP positive was 16.97 months, which is significantly lower than those of T3 stage, $30.5(p<0.001)$ in AFP negative and $17.66(p=0.181)$ in AFP positive, respectively. However, to the patients with AFP negative was 24 months, which is superior than those of T3 stage, $30.5(p=0.255)$ in AFP negative and $17.66(p=0.285)$ in AFP positive, respectively (Table S1).

\section{Prognosis of HCC after incorporation of AFP into TNM staging}

Univariate and multivariate analysis were used to analyzed the influences of the incorporation of AFP into the AJCC staging. We calculated the 5-year OS and DSS separately for various AJCC and AFP stage combinations, such as stages I A0, I A1, II A0, II A1, and so on (Table 4). Multivariate analysis was performed by the Cox regression model, as is shown in Table 5. Combined these two tables, we made 2 major observations. First, within each AJCC stage, patients with A1 disease had a worse prognosis compared with those with A0 disease. For example, DSS of stage I A1 was worse than I A0 (31.43\% vs $52.8 \%, p<0.001)$, and so on. Second, the magnitude of the difference in survival between patients with $\mathrm{A} 0$ and $\mathrm{A} 1$ disease within each stage was large enough, the prognosis of patients with A1 disease of lower AJCC stages was worse than or similar to that of patients with A0 disease of higher AJCC stages. This finding can be gleaned by observing the overlap of the $95 \%$ CIs. For example, disease-specific mortality of patients with stage IIIA A1 (HR, 4.252; 95\% CI, 3.839-4.709) is higher than that of patients with stage IIIC A0 (HR, 3.220; 95\% CI, 2.654-3.907), 
Table 1: Univariate survival analysis of AFP on OS and DSS based on different histological types via standard Kaplan-Meier estimates

\begin{tabular}{cccccc}
\hline \multicolumn{1}{c}{ Variable } & $\boldsymbol{n}$ & 5-year OS (\%) & $\boldsymbol{P}$ value & 5-year DSS (\%) & $\boldsymbol{P}$ value \\
\hline HCC & 2660 & 31 & & 38 & \\
A0 & 9339 & 15 & $<0.001$ & 19 & $<0.001$ \\
A1 & & & & 12 & \\
ICC & 544 & 11 & .230 & 9 & .236 \\
A0 & 252 & 7 & & & \\
A1 & 35 & 15 & .742 & 24 & .751 \\
Combined & 78 & 18 & 23 & \\
A0 & & & & & \\
A1 &
\end{tabular}

Abbreviations: OS, overall survival. DSS, disease-specific survival. HCC, hepatocellular carcinoma. ICC, intrahepatic cholangiocarcinoma. Combined, HCC and ICC.

and patients with stage IIIC A1 disease (HR, 5.719; 95\% CI, 5.092-6.422) is similar to that of patients with stage IV A0 disease (HR, 5.902; 95\% CI, 5.121-6.802). I A0, T1 A0 and N0 A0 stages served as control. A similar pattern can be observed in OS outcomes as well.

Subsequently, we analyzed the association of various combinations of $\mathrm{T} / \mathrm{N}$ and AFP stages with prognosis to understand the interaction of primary tumor and lymph nodes with AFP status (Table 5). We calculated the hazards for overall and disease-specific mortality along with the respective $95 \% \mathrm{CIs}$, compared the outcomes among various combinations. T1 A0 and N0 A0 stages served as control. Again, we observed that patients with A1 disease of each $\mathrm{T} / \mathrm{N}$ stage had a worse prognosis than patients with $\mathrm{A} 0$ disease of the respective stage, and the prognosis of patients with $\mathrm{A} 1$ disease with lower $\mathrm{T}$ stages was worse or similar to that of patients with $\mathrm{A} 0$ disease of higher $\mathrm{T}$ stages.

This phenomenon is better illustrated in the KaplanMeier curves (Figure 2A and 2B), where the curves of patients with A0 disease of certain AJCC stages appear to be grouped or clustered, whereas the curves of patients with $\mathrm{C} 1$ disease of the respective AJCC stages appear to be clustered separately.

\section{DISCUSSION}

This study analyzed the long-term prognosis of patients with histologically proven HCC after the incorporation of their pretreatment serum AFP level into the TNM staging system. The large US population-based SEER database was used to collect patient data.

Our previous cohort consisted of 12908 unique records. Nevertheless, the patients with ICC or combined were eliminated after an univariate analysis, because no significant differences $(P>0.05)$ on OS and DSS were observed between $\mathrm{A} 0$ and $\mathrm{A} 1$ groups of these two histological types. As described by other investigators, HCC tumor markers are AFP and protein induced by vitamin $\mathrm{K}$ absence or antagonist II,while ICC tumor markers are carcinoembryonic antigen (CEA) and carbohydrate antigen 19-9 (CA19-9). ICC accounts for approximately $5 \%$ of primary liver cancers and AFP positive ICC accounts for less than 1\% [13, 14]. Hence, patients with histologically proven $\mathrm{HCC}$ were used for statistical analyses.

A prerequisite to proceed with the inclusion of AFP into the staging system is confirmation of AFP as an independent prognostic factor for $\mathrm{HCC}$ patients. In this study, we demonstrated that AFP satisfy this prerequisite via multivariate regression analyses. We identified a subset of patients in each AJCC stage by A1 status and noted that OS and DSS of this subset were worse than or similar to a subset of A0 status patients who belonged to a higher AJCC stage. Furthermore, we have proved this phenomenon in the stratified analysis of $\mathrm{T}$ stage. These findings indicate the important predictive value of including AFP into the conventional TNM staging and raise the probability of undertreatment of specific HCC patients. Additionally, a global, multicenter, randomized, double-blind, phase 3 REACH study proved that AFP could be a predictive marker for ramucirumab (a secondline treatment in patients with advanced HCC) survival benefit [15]. Similarly, higher AFP level should be considered as an indicator of poor prognosis after liver transplantation [16-18]. Absolutely, AFP seems to be a potential subclassification factor.

However, the patient data extracted from the SEER database was limited to AJCC 6th stage. In 2010, the AJCC updated the arrangement of these TNM combinations [19]. The main variation is the refinement of T3 stage, with redefining T3a as large multinodular and T3b as a major branch of the portal vein or hepatic vein involved. New staging system was regarded to be more active in clinical practice. However, the BCLC is the only staging system with a treatment recommendation based on the stage in West [8]. When integrated into clinical protocols, the results of our study may provide a novel paradigm of HCC management, which depends on the BCLC stage and AJCC stage. 
Table 2: Comparison of patients with $\mathrm{A0}$ and $\mathrm{A1}$ disease

\begin{tabular}{|c|c|c|c|c|}
\hline \multirow[b]{2}{*}{ Characteristic } & \multicolumn{3}{|c|}{ NO.(\%) of patients } & \multirow{2}{*}{$\begin{array}{c}P \text { value }\left(\chi^{2} \text { or }\right. \\
\text { Student's } t \text {-test) }\end{array}$} \\
\hline & All $(N=11999)$ & $\operatorname{A0}(N=2660)$ & A1 $(N=9339)$ & \\
\hline \multicolumn{5}{|l|}{ Age, $y$} \\
\hline$\leq 45$ & $733(6.1)$ & $186(7.0)$ & $547(5.9)$ & \multirow{2}{*}{.031} \\
\hline$>45$ & $11266(93.9)$ & $2474(93.0)$ & $8792(94.1)$ & \\
\hline \multicolumn{5}{|l|}{ Sex } \\
\hline Male & $9344(77.9)$ & $2094(78.7)$ & $7250(77.6)$ & \multirow{2}{*}{.232} \\
\hline Female & $2655(22.1)$ & $566(21.3)$ & $2089(22.4)$ & \\
\hline \multicolumn{5}{|l|}{ Race } \\
\hline White & 7727 (64.4) & $1921(72.2)$ & $5806(62.2)$ & \multirow{4}{*}{$<0.001$} \\
\hline Black & $1618(13.5)$ & $217(8.2)$ & $1401(15.0)$ & \\
\hline Other & 2624 (21.9) & $513(19.3)$ & $2111(22.6)$ & \\
\hline Unknown & $30(0.3)$ & $9(0.3)$ & $21(0.2)$ & \\
\hline \multicolumn{5}{|l|}{ Pathological grade ${ }^{a}$} \\
\hline I-II & $3545(29.5)$ & $1109(41.7)$ & $2436(26.1)$ & \multirow{3}{*}{$<0.001$} \\
\hline III-IV & $1212(10.1)$ & $207(7.8)$ & $1005(10.8)$ & \\
\hline Unknown & $7242(60.4)$ & $1344(50.5)$ & $5898(63.2)$ & \\
\hline \multicolumn{5}{|l|}{ Surgery } \\
\hline Surgery & $3736(31.1)$ & $1147(43.1)$ & $2589(27.7)$ & \multirow{3}{*}{$<0.001$} \\
\hline No surgery & $8115(67.6)$ & $1474(55.4)$ & $6641(71.1)$ & \\
\hline Unknown & $148(1.2)$ & $39(1.5)$ & 109 (1.2) & \\
\hline \multicolumn{5}{|l|}{ 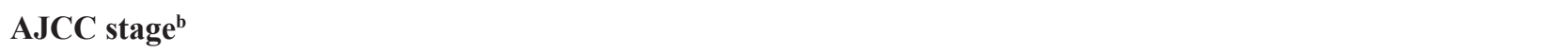 } \\
\hline I & $4087(34.1)$ & $1224(46.0)$ & $2863(30.7)$ & \multirow{6}{*}{$<0.001$} \\
\hline II & $2466(20.6)$ & $572(21.5)$ & $1894(20.3)$ & \\
\hline IIIA & $2071(17.3)$ & $333(12.5)$ & $1738(18.6)$ & \\
\hline IIIB & $258(2.2)$ & $42(1.6)$ & $216(2.3)$ & \\
\hline IIIC & $970(8.1)$ & $169(6.4)$ & $801(8.6)$ & \\
\hline IV & $2147(17.9)$ & $320(12.0)$ & $1827(19.6)$ & \\
\hline \multicolumn{5}{|l|}{ T stage st $^{b}$} \\
\hline $\mathrm{T} 1$ & 4729 (39.4) & $1352(50.8)$ & $3377(36.2)$ & \multirow{5}{*}{$<0.001$} \\
\hline $\mathrm{T} 2$ & 2873 (23.9) & $646(24.3)$ & $2227(23.8)$ & \\
\hline $\mathrm{T} 3$ & $3147(26.2)$ & $479(18.0)$ & $2668(28.6)$ & \\
\hline $\mathrm{T} 4$ & $627(5.2)$ & $88(3.3)$ & $539(5.8)$ & \\
\hline Tx & $623(5.2)$ & $95(3.6)$ & $528(5.7)$ & \\
\hline \multicolumn{5}{|l|}{ N stage ${ }^{b}$} \\
\hline N0 & $10014(83.5)$ & $2346(88.2)$ & 7668 (82.1) & \multirow{3}{*}{$<0.001$} \\
\hline N1 & 1405 (11.7) & $237(8.9)$ & $1168(12.5)$ & \\
\hline $\mathrm{Nx}$ & $580(4.8)$ & $77(2.9)$ & $503(5.4)$ & \\
\hline \multicolumn{5}{|l|}{ M stage ${ }^{b}$} \\
\hline M0 & 9367 (78.1) & $2262(85.0)$ & 7105 (76.1) & \multirow{3}{*}{$<0.001$} \\
\hline M1 & $2582(21.5)$ & $388(14.6)$ & $2194(23.5)$ & \\
\hline $\mathrm{Mx}$ & $50(0.4)$ & $10(0.4)$ & $40(0.4)$ & \\
\hline
\end{tabular}

Abbreviations: AJCC, American Joint Committee on Cancer.

${ }^{a}$ Grade I: well differentiated, II: moderately differentiated, III: poorly differentiated, IV: undifferentiated.

${ }^{\mathrm{b}}$ AJCC Cancer Staging Handbook 6th Edition. 
Table 3: Multivariate Cox model analyses for overall and disease-specific mortality

\begin{tabular}{|c|c|c|c|c|}
\hline \multirow{2}{*}{ Variable } & \multicolumn{2}{|c|}{ Overall Mortality } & \multicolumn{2}{|c|}{ Disease-Specific Mortality } \\
\hline & HR $(95 \%$ CI) & $P$ value & HR (95\% CI) & $P$ value \\
\hline \multicolumn{5}{|l|}{ Year of diagnosis } \\
\hline 2008 & 1 [Reference] & & 1 [Reference] & \\
\hline 2007 & $1.024(1.009-1.013)$ & .424 & $1.200(1.120-1.286)$ & $<0.001$ \\
\hline 2006 & $1.068(1.004-1.135)$ & .036 & $1.079(1.009-1.154)$ & .026 \\
\hline 2005 & $1.098(1.032-1.169)$ & .003 & $1.059(0.992-1.130)$ & .084 \\
\hline 2004 & $1.216(1.139-1.297)$ & $<0.001$ & $1.200(1.120-1.286)$ & .749 \\
\hline \multicolumn{5}{|l|}{ Sex } \\
\hline Female & $1[$ Reference $]$ & & 1 [Reference] & \\
\hline Male & $1.068(1.016-1.122)$ & $<0.001$ & $1.044(0.990-1.100)$ & .109 \\
\hline \multicolumn{5}{|l|}{ Race } \\
\hline White & 1 [Reference] & & 1 [Reference] & \\
\hline Black & $1.123(1.059-1.190)$ & $<0.001$ & $1.115(1.048-1.187)$ & .001 \\
\hline Other & $0.823(0.781-0.866)$ & $<0.001$ & $0.822(0.778-0.869)$ & $<0.001$ \\
\hline Unknown & $0.728(0.447-1.108)$ & .139 & $0.660(0.415-1.050)$ & .079 \\
\hline \multicolumn{5}{|c|}{ Pathological grade } \\
\hline $\mathrm{I}-\mathrm{II}$ & 1 [Reference] & & 1 [Reference] & \\
\hline III-IV & $1.326(1.230-1.428)$ & $<0.001$ & $1.347(1.245-1.457)$ & $<0.001$ \\
\hline Unknown & $1.201(1.144-1.261)$ & $<0.001$ & $1.199(1.138-1.263)$ & $<0.001$ \\
\hline \multicolumn{5}{|l|}{ Surgery } \\
\hline No & 1 [Reference] & & 1 [Reference] & \\
\hline Yes & $0.770(0.642-0.924)$ & $<0.001$ & $0.711(0.580-0.873)$ & .001 \\
\hline Unknown & $0.362(0.343-0.383)$ & .005 & $0.356(0.336-0.378)$ & $<0.001$ \\
\hline \multicolumn{5}{|l|}{ AFP stage } \\
\hline A0 & 1 [Reference] & & 1 [Reference] & \\
\hline A1 & $1.460(1.385-1.539)$ & $<0.001$ & $1.514(1.430-1.603)$ & $<0.001$ \\
\hline \multicolumn{5}{|l|}{ T stage } \\
\hline $\mathrm{T} 1$ & 1 [Reference] & & 1 [Reference] & \\
\hline $\mathrm{T} 2$ & $1.025(0.970-1.083)$ & .376 & $0.982(0.925-1.043)$ & .559 \\
\hline $\mathrm{T} 3$ & $1.681(1.555-1.748)$ & $<0.001$ & $1.748(1.653-1.848)$ & $<0.001$ \\
\hline T4 & $1.593(1.451-1.748)$ & $<0.001$ & $1.676(1.522-1.845)$ & $<0.001$ \\
\hline $\mathrm{Tx}$ & $1.719(1.557-1.897)$ & $<0.001$ & $1.780(0.609-1.968)$ & $<0.001$ \\
\hline \multicolumn{5}{|l|}{ N stage } \\
\hline N0 & 1 [Reference] & & 1 [Reference] & \\
\hline N1 & $1.052(0.982-1.127)$ & .146 & $1.027(0.956-1.103)$ & .472 \\
\hline $\mathrm{Nx}$ & $1.208(1.092-1.337)$ & $<0.001$ & $1.219(1.101-1.350)$ & $<0.001$ \\
\hline \multicolumn{5}{|l|}{ M stage } \\
\hline M0 & 1 [Reference] & & 1 [Reference] & \\
\hline M1 & $1.757(1.650-1.870)$ & $<0.001$ & $1.986(1.862-2.119)$ & $<0.001$ \\
\hline $\mathrm{Mx}$ & $2.189(1.638-2.925)$ & $<0.001$ & $2.277(1.672-3.102)$ & $<0.001$ \\
\hline
\end{tabular}

Abbreviations: HR, hazard ratio. 
For further discussion, we analyzed the similarities and differences among the BCLC, the AJCC (6th) and AJCC (7th ) staging system. In the United States, the paradigm for treatment of $\mathrm{HCC}$ has been BCLC stage specific. Stage 0 is treated with surgical resection alone, stage A with radical therapies (resection, liver transplantation (LT), percutaneous ethanol injection (PEI) or radiofrequency thermal ablation (RFA)), stage $B$ with transarterial chemoembolization (TACE), stage $\mathrm{C}$ with new agents in the setting of RCTs (sorafenib, etc.) and stage D with symptomatic treatment (Figure 3) [20]. Following this recommendation, the 5-year OS of the population in stage 0, A was 40-70\% without controversy. Nevertheless, new data proved that not following the recommended treatment resulted in a better outcome among the more severe stages (B-D) $[8,20,21]$. Some studies indicated that a more aggressive treatment would yield a better outcome to those patients in stage B or C $[22,23]$. In 2012, Bolondi et al. utilized a novel calssification system by modifying the BCLC, especially stage B [24]. Thus, there is controversy regarding the management paradigm of stage $B$ and $C$, which are discussed in detail below.

According to the AJCC (6th) staging manual, BCLC $\mathrm{B}$ is equal to parts of stage $\mathrm{T} 3$ and $\mathrm{C}$ is equal to part of stage T3 and T4, respectively [25]. Currently, patients with BCLC B are generally treated with TACE, and patients with BCLC C are treated with sorafenib alone. Thus, the decision to recommend radical therapy is often driven mainly by tumor invasion status. In our study, within each T substage, A1 disease predicted poor prognosis compared with patients with A 0 disease and the corresponding $\mathrm{T}$ stages. Moreover, analysis of every combination of $\mathrm{T}$ stage and AFP stage showed that high AFP level disease predicted poor prognosis to a similar magnitude as early $\mathrm{T}$ disease. We can conclude that patients with circumscribed HCC with elevated AFP levels may have a poor prognosis similar to those with extra-hepatic spread disease. Therefore, AFP may be integrated into BCLC C stage as a subclassification factor.

Based on these insights and our results, we proposed a subclassification of BCLC B and C stage, as is shown in Table 6. In patients with stage B, we still follow the staging paradigm and recommended treatment proposed by Bolondi et al. However, for patients with stage $\mathrm{C}$, we used a novel subclassification. Patients with A0 in stage $\mathrm{C}$, defined as $\mathrm{C} 1$, are suggested to receive resection, leaving patients with moderate to severe cirrhosis. Liu et al. study demonstrated a better overall survival of surgical resection than transarterial chemoembolization (TACE) in HCC patients with BCLC stage C [26]. LT is the optimal treatment even for small, otherwise resectable HCC. However, limited organ availability mandates the restriction of transplantation to only those patients with early stage tumors [27]. Moreover, preoperative treatment can apply to decrease tumor burden to fulfill listing criteria of resection or transplantation and to improve survival. The preoperative treatment includes percutaneous injection of ethanol (PEI) or acetic acid (PAI), RFA, TACE or transarterial embolization (TAE), radioactive microspheres, and stereotactic radiation. Data suggested that preoperative therapy downstaged the primary tumors and improved survival [28]. To investigate the benefit of surgery treatment for specific population, we conducted the survival analysis layering for surgical treatment of patients with non-surgical treatment of T3 and T4 patients with different AFP status. Our results shows that the 5-year OS of patients in $\mathrm{T} 4 \mathrm{~S}+\mathrm{A}+(\mathrm{T} 4$ patients with surgery treatment and AFP positive) was significantly
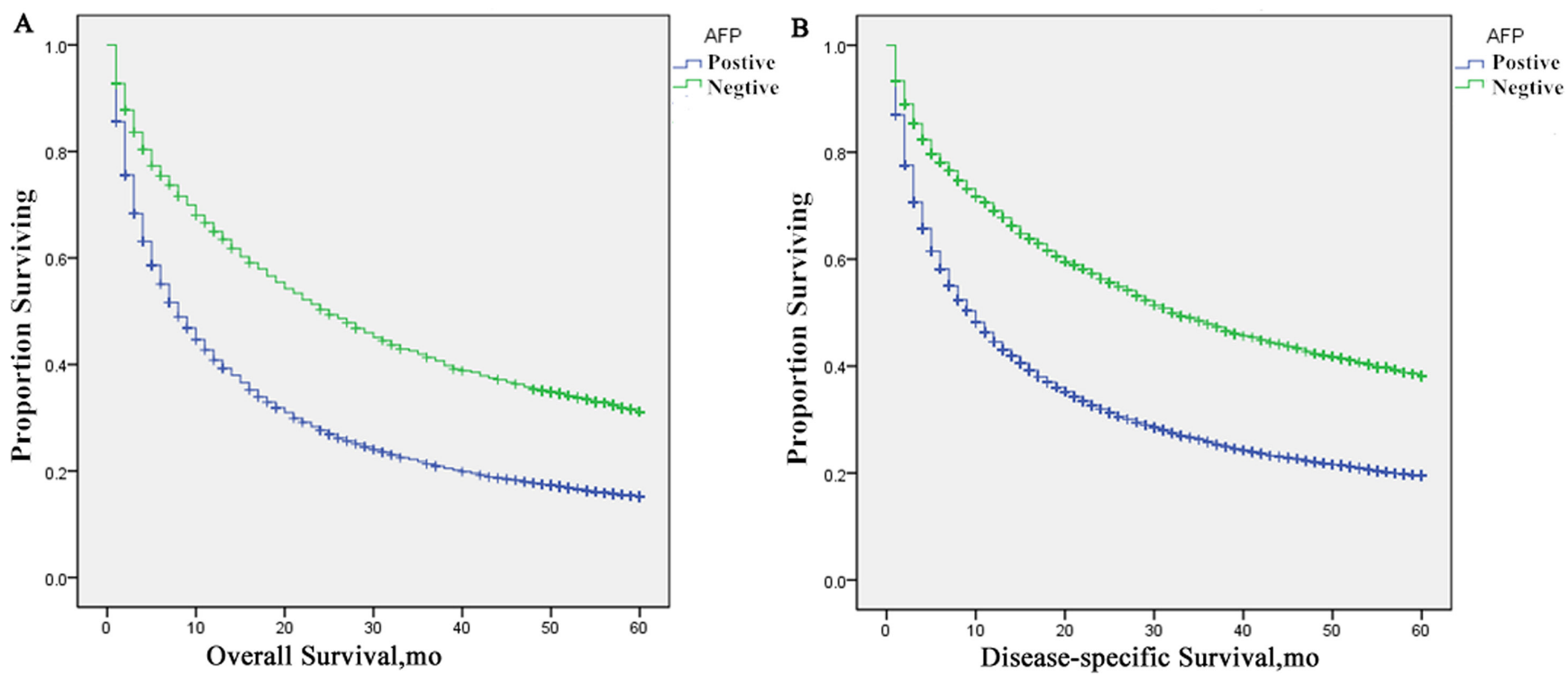

Figure 1: Survival curves in patients according to AFP status via standard Kaplan-Meier estimates. (A) 5-year OS: AFP positive patients vs. negative patients, $\chi^{2}=472.190, P<0.001$; (B) 5-year DSS: AFP positive patients vs. negative patients, $\chi^{2}=477.292 P<0.001$. 
Table 4: Univariate analysis of AFP on OS and DSS based on different stages via standard Kaplan-Meier estimates

\begin{tabular}{|c|c|c|c|c|c|}
\hline Variable & $n$ & 5-year OS (\%) & $P$ value & 5-year DSS (\%) & $P$ value \\
\hline \multicolumn{6}{|l|}{ I } \\
\hline A 0 & 1224 & 41.89 & \multirow{2}{*}{$<0.001$} & 52.80 & \multirow{2}{*}{$<0.001$} \\
\hline A1 & 2863 & 25.79 & & 31.43 & \\
\hline \multicolumn{6}{|l|}{ II } \\
\hline A0 & 572 & 38.18 & \multirow{2}{*}{$<0.001$} & 48.64 & \multirow{2}{*}{$<0.001$} \\
\hline $\mathrm{A} 1$ & 1894 & 25.57 & & 34.25 & \\
\hline \multicolumn{6}{|l|}{ IIIA } \\
\hline A0 & 333 & 13.65 & \multirow{2}{*}{$<0.001$} & 13.65 & \multirow{2}{*}{$<0.001$} \\
\hline A1 & 1738 & 5.39 & & 7.79 & \\
\hline \multicolumn{6}{|l|}{ IIIB } \\
\hline $\mathrm{A} 0$ & 42 & 17.69 & \multirow{2}{*}{.008} & 18.16 & \multirow{2}{*}{.028} \\
\hline A1 & 216 & 7.80 & & 10.42 & \\
\hline \multicolumn{6}{|l|}{ IIIC } \\
\hline A0 & 169 & 10.53 & \multirow{2}{*}{$<0.001$} & 13.65 & \multirow{2}{*}{$<0.001$} \\
\hline $\mathrm{A} 1$ & 801 & 4.09 & & 5.90 & \\
\hline \multicolumn{6}{|l|}{ IV } \\
\hline $\mathrm{A} 0$ & 320 & 1.92 & \multirow{2}{*}{$<0.001$} & 1.92 & \multirow{2}{*}{$<0.001$} \\
\hline $\mathrm{A} 1$ & 1827 & 1.61 & & 1.61 & \\
\hline \multicolumn{6}{|l|}{ T1 } \\
\hline A0 & 1352 & 39.24 & \multirow{2}{*}{$<0.001$} & 49.09 & \multirow{2}{*}{$<0.001$} \\
\hline A1 & 3377 & 22.43 & & 27.26 & \\
\hline \multicolumn{6}{|l|}{$\mathrm{T} 2$} \\
\hline A0 & 646 & 34.65 & \multirow{2}{*}{$<0.001$} & 43.94 & \multirow{2}{*}{$<0.001$} \\
\hline $\mathrm{A} 1$ & 2227 & 22.44 & & 29.84 & \\
\hline \multicolumn{6}{|l|}{ T3 } \\
\hline A0 & 479 & 9.91 & \multirow{2}{*}{$<0.001$} & 10.32 & \multirow{2}{*}{$<0.001$} \\
\hline A1 & 2668 & 4.10 & & 5.78 & \\
\hline \multicolumn{6}{|l|}{ T4 } \\
\hline A0 & 88 & 8.28 & & 8.55 & \\
\hline A1 & 539 & 4.65 & $<0.001$ & 5.70 & $<0.001$ \\
\hline No & & & & & \\
\hline A0 & 2346 & 33.85 & (1) & 41.66 & - \\
\hline A1 & 7668 & 17.66 & $<0.001$ & 22.63 & $<0.001$ \\
\hline N1 & & & & & \\
\hline A0 & 237 & 9.17 & $<0001$ & 11.19 & $<0001$ \\
\hline A1 & 1168 & 3.59 & $<0.001$ & 4.76 & $<0.001$ \\
\hline
\end{tabular}

Abbreviations: OS, overall survival. DSS, disease-specific survival.

lower than those of $\mathrm{T} 3 \mathrm{~S}+\mathrm{A}+(\mathrm{T} 3$ patients with surgery treatment and AFP positive) and $\mathrm{T} 3 \mathrm{~S}+\mathrm{A}-(\mathrm{T} 3$ patients with surgery treatment and AFP negative). Interestingly, patients in $\mathrm{T} 4 \mathrm{~S}+\mathrm{A}-(\mathrm{T} 4$ patients with surgery treatment and AFP negative) group showed similar prognosis on 5 -year OS with those in $\mathrm{T} 3 \mathrm{~S}+\mathrm{A}+$ and $\mathrm{T} 3 \mathrm{~S}+\mathrm{A}-$ groups. Hence, we recommended actively surgery treatment for patients in BCLC C0 stage. Meanwhile, the response to locoregional treatment predicted post-transplant outcome and that this response may be used for patient selection. Furthermore, an AFP level greater than $200 \mathrm{ng} / \mathrm{mL}$ was associated with a 3.32-folds increase in the probability of HCC recurrence after LT as reported by Schraiber et al [29]. Besides, transarterial radioembolization (TARE) with yttrium-90 was proved superior to TACE in the treatment of advanced HCC in various studies [30-32]. Percutaneous ablation treatment is not suitable for large HCCs due to the risks of diffusion, vascular washout, and heterogeneity. Patents with A1 in stage C, defined as $\mathrm{C} 2$, are suggested to receive new agents in the setting of RCTs (sorafenib, etc.). Sorafenib, an inhibitor of Raf-1, B-Raf, the receptor tyrosine kinases vascular endothelial growth 
Table 5: Multivariate Cox model analysis of prognostic factors of $\mathrm{HCC}$ on different stages

\begin{tabular}{|c|c|c|c|c|c|}
\hline \multirow{2}{*}{ Variable } & \multirow{2}{*}{$n$} & \multicolumn{2}{|c|}{ Overall Mortality } & \multicolumn{2}{|c|}{ Disease-specific Mortality } \\
\hline & & HR (95\% CI) & $P$ value & HR $(95 \%$ CI $)$ & $P$ value \\
\hline \multicolumn{6}{|l|}{ I } \\
\hline A0 & 1224 & 1 [Reference] & & 1 [Reference] & \\
\hline A1 & 2863 & $1.652(1.516-1.801)$ & $<0.001$ & $1.924(1.744-2.124)$ & $<0.001$ \\
\hline \multicolumn{6}{|l|}{ II } \\
\hline A0 & 572 & $1.100(0.966-1.252)$ & .149 & $1.123(0.966-1.304)$ & .131 \\
\hline A1 & 1894 & $1.611(1.471-1.765)$ & $<0.001$ & $1.742(1.568-1.935)$ & $<0.001$ \\
\hline \multicolumn{6}{|l|}{ IIIA } \\
\hline A0 & 333 & $2.270(1.968-2.617)$ & $<0.001$ & $3.080(2.652-3.576)$ & $<0.001$ \\
\hline $\mathrm{A} 1$ & 1738 & $3.573(3.266-3.909)$ & $<0.001$ & $4.252(3.839-4.709)$ & $<0.001$ \\
\hline \multicolumn{6}{|l|}{ IIIB } \\
\hline A0 & 42 & $2.157(1.529-3.044)$ & $<0.001$ & $2.839(1.996-4.037)$ & $<0.001$ \\
\hline A1 & 216 & $3.549(3.025-4.163)$ & $<0.001$ & $4.415(3.720-5.239)$ & $<0.001$ \\
\hline \multicolumn{6}{|l|}{ IIIC } \\
\hline A0 & 169 & $2.758(2.310-3.293)$ & $<0.001$ & $3.220(2.654-3.907)$ & $<0.001$ \\
\hline $\mathrm{A} 1$ & 801 & $4.767(4.295-5.291)$ & $<0.001$ & $5.719(5.092-6.422)$ & $<0.001$ \\
\hline \multicolumn{6}{|l|}{ IV } \\
\hline A0 & 320 & $4.395(3.842-5.028)$ & $<0.001$ & $5.902(5.121-6.802)$ & $<0.001$ \\
\hline A1 & 1827 & $6.490(5.929-7.104)$ & $<0.001$ & $8.550(7.727-9.460)$ & $<0.001$ \\
\hline \multicolumn{6}{|l|}{ T1 } \\
\hline A0 & 1352 & 1 [Reference] & & 1 [Reference] & \\
\hline A1 & 3377 & $1.718(1.587-1.860)$ & $<0.001$ & $1.962(1.795-2.146)$ & $<0.001$ \\
\hline \multicolumn{6}{|l|}{$\mathbf{T 2}$} \\
\hline A0 & 646 & $1.119(0.994-1.260)$ & .064 & $1.142(0.998-1.307)$ & .054 \\
\hline A1 & 2227 & $1.665(1.531-1.811)$ & $<0.001$ & $1.788(1.626-1.966)$ & $<0.001$ \\
\hline \multicolumn{6}{|l|}{ T3 } \\
\hline A0 & 479 & $2.508(2.225-2.827)$ & $<0.001$ & $3.176(2.798-3.606)$ & $<0.001$ \\
\hline A1 & 2668 & $3.705(3.418-4.017)$ & $<0.001$ & $4.332(3.958-4.742)$ & $<0.001$ \\
\hline \multicolumn{6}{|l|}{ T4 } \\
\hline A0 & 88 & $2.585(2.054-3.254)$ & $<0.001$ & $3.253(2.570-4.118)$ & $<0.001$ \\
\hline A1 & 539 & $4.331(3.871-4.846)$ & $<0.001$ & $5.306(4.705-5.983)$ & $<0.001$ \\
\hline \multicolumn{6}{|l|}{ No } \\
\hline A0 & 2346 & 1 [Reference] & & 1 [Reference] & \\
\hline A1 & 7668 & $1.711(1.617-1.810)$ & $<0.001$ & $1.809(1.700-1.924)$ & $<0.001$ \\
\hline \multicolumn{6}{|l|}{ N1 } \\
\hline A0 & 237 & $2.252(1.950-2.600)$ & $<0.001$ & $2.444(2.100-2.845)$ & $<0.001$ \\
\hline A1 & 1168 & $3.747(3.463-4.054)$ & $<0.001$ & $4.122(3.790-4.483)$ & $<0.001$ \\
\hline
\end{tabular}

Abbreviations: HR, hazard ratio.

factor receptors (VEGFRs) 1, 2 and 3, and platelet derived growth factor receptor $\beta$ (PDGFR- $\beta$ ), is now considered as a first-line agent for patients with more advanced HCC. Short-term sorafenib treatment was a potential strategy for recurrence prevention after partial hepatectomy in early-stage HCC. New data has proven its efficacy and safety [33-35]. Moreover, sorafenib is also recommended for patients who have failed TACE or can no longer be treated with more effective therapies [36]. Oherwise, CWP232228, a small molecule inhibitor targeting liver cancer stem cells through Wnt/betacatenin signaling, can also served as a selection [37]. The efficacy and safety of immunosuppression and adjuvant chemotherapy remains to be discussed. In summary, radical treatment may achieve a better prognosis for patients with $\mathrm{A} 0$ in BCLC C than traditional BCLC-based recommendation treatment. Further long-term clinical studies remain to be conducted to evaluate and modify the extensional scheme.

Taken together, AFP can act as an independent prognostic factor for HCC. Regression analysis indicates that incorporating AFP level into HCC staging system is superior to original AJCC stage in predicting prognosis 

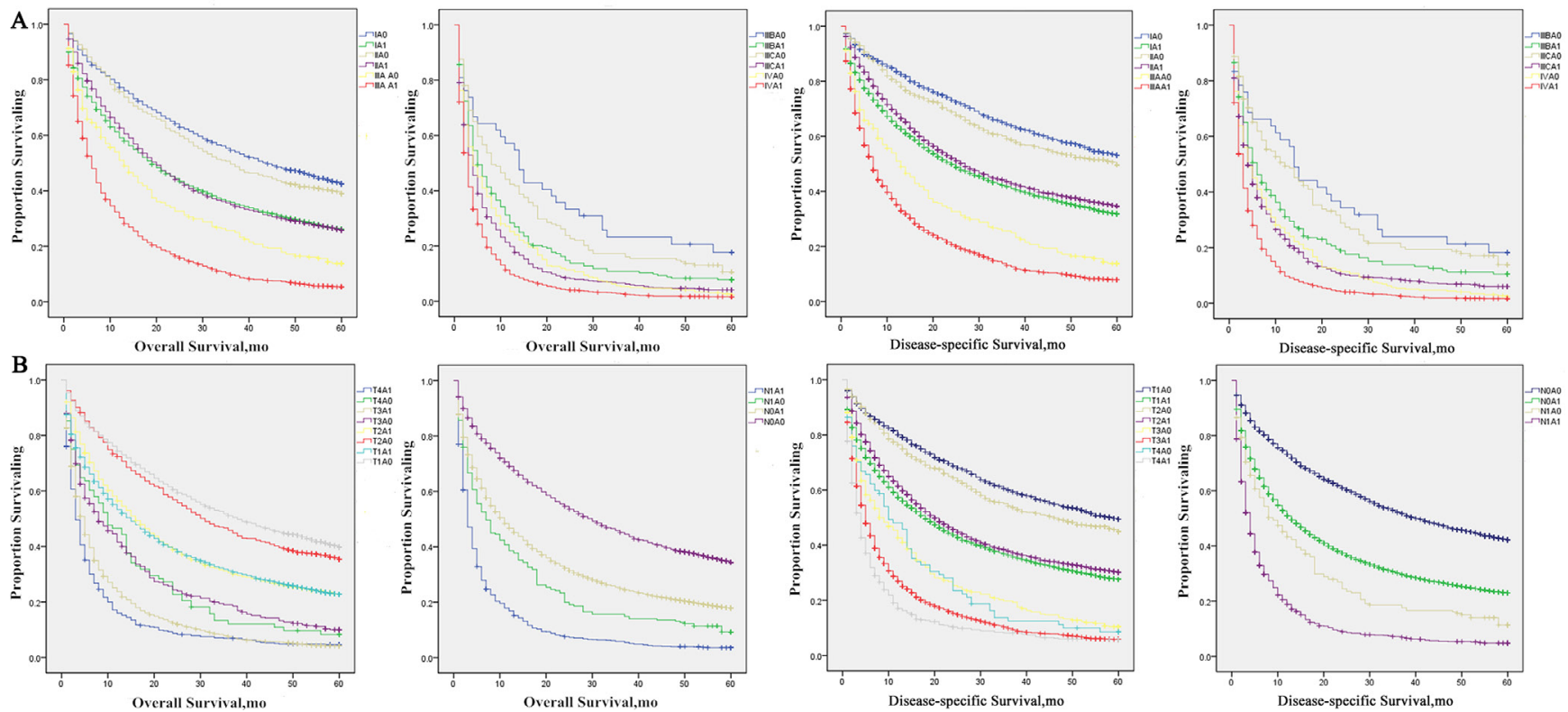

Figure 2: Survival curves in patients according to AFP status combined with each AJCC stage or T/N stage via standard Kaplan-Meier estimates. (A) 5-year OS and LSS of patients with different combinations of AFP status and each AJCC stage. (B) 5-year OS and LSS of patients with different combinations of AFP status and each T/N stage.

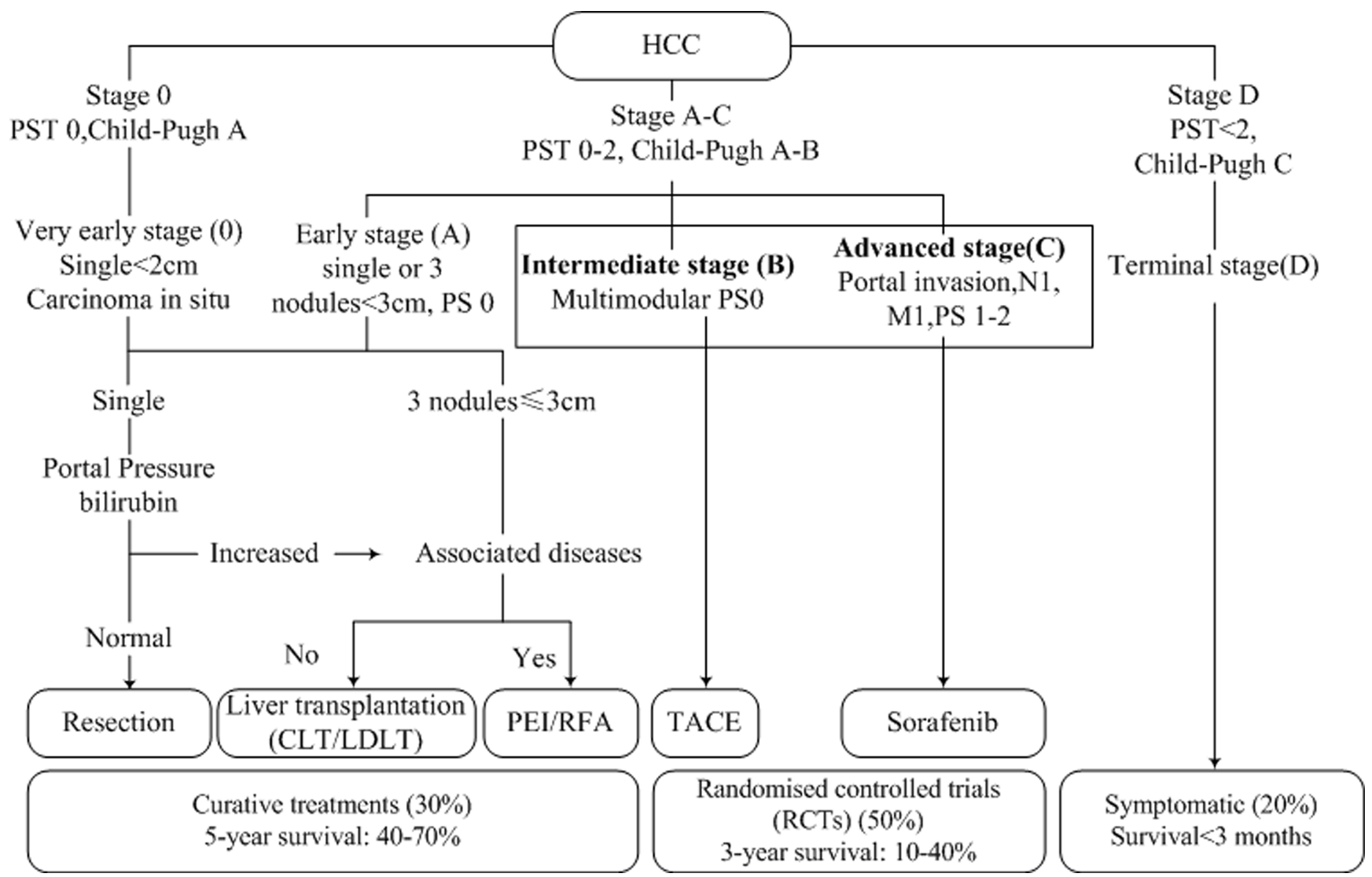

Figure 3: The BCLC stage system and recommended treatment strategies. 
Table 6: Subclassification and treatment strategy of intermediate and advanced stage HCC

\begin{tabular}{|c|c|c|c|c|c|c|}
\hline BCLC stage & \multicolumn{4}{|l|}{ B } & \multicolumn{2}{|l|}{ C } \\
\hline PS & \multicolumn{4}{|l|}{0} & \multicolumn{2}{|l|}{$1-2$} \\
\hline Tumor size & \multicolumn{4}{|c|}{ Large, multinodular } & \multicolumn{2}{|c|}{$\begin{array}{l}\text { Vascular invasion/ } \\
\text { Extrahepatic spread }\end{array}$} \\
\hline Okuda stage & \multicolumn{4}{|l|}{ I-II } & \multicolumn{2}{|l|}{ I-II } \\
\hline Child-Pugh score & $\begin{array}{l}5-7 \\
\text { B1 }\end{array}$ & & $\begin{array}{l}8-9 \\
\text { B2 }\end{array}$ & & \multicolumn{2}{|l|}{$5-9$} \\
\hline Beyond Milan and within up-to-7/AFP & IN & OUT & IN & OUT & A0 & A1 \\
\hline Substage & B1a & B1b & B2a & B2b & C1 & $\mathrm{C} 2$ \\
\hline Treatment option & $\begin{array}{l}\text { Resection } \\
\text { Ablation } \\
\text { cTACE }\end{array}$ & $\begin{array}{l}\text { DEB-TACE } \\
\text { HAIC } \\
\text { Sorafenib }\end{array}$ & $\begin{array}{l}\text { LT } \\
\text { Ablation } \\
\text { cTACE }\end{array}$ & $\begin{array}{l}\text { HAIC } \\
\text { DEB-TACE }\end{array}$ & $\begin{array}{l}\text { Resection/LT }{ }^{1} \\
\text { TARE }^{2} \\
\text { Sorafenib }\end{array}$ & $\begin{array}{l}\text { Sorafenib } \\
\text { CWP2322283 }\end{array}$ \\
\hline
\end{tabular}

Abbreviations: PS, performance scale. LT, liver transplantation.

${ }^{1}$ Resection is recommended for those patients leaving moderate to severe cirrhosis. LT is the optimal treatment if organ availability. Preoperative treatments are recommended.

${ }^{2}$ TARE can be used as preoperative treatment or for whom surgery is inappropriate.

${ }^{3} \mathrm{CWP} 232228$ and other new agents in the setting of RCTs.

and selecting more effective treatment. Perhaps more importantly, we can distinguish the population who are more likely to benefit from active treatment and improve survival rate. Much remains to be improved in the staging and treatment of HCC.

Our study mainly investigated the relationship between the expression of AFP and clinical prognosis of HCC patients. We will continue our further research in vitro. Some researchers have studied the effects of AFP on liver cancer cell growth, migration, and apoptosis. Over the past few decades, professor Mengsen Li with his partners have been addressing the connection between AFP and liver cancer cell growth, apoptosis and drug resistance. Their studies demonstrated that AFP and AFPR may play pivotal role in HBV-related malignant transformation of hepatocytes via the activation of PI3K/mTOR signaling pathway. Actuated expression of AFPR plays a role of an indicator suitable for use in the early diagnosis of $\mathrm{HBx}$ driven malignant transformation of hepatocytes. Labeled AFPR is likely to trace primary and metastatic HCC $[38,39]$. Furthermore, AFP is an important molecule acting against paclitaxel-induced proliferation inhibition and apoptosis in HCC cells, which indicated that inhibiting AFP expression after treatment with paclitaxel may be an available strategy for the treatment of HCC [40]. Besides, AFP plays a crucial role in promoting metastasis of $\mathrm{HCC}$ via up-regulating expression of metastasis-related proteins [41].

The AFP could be a regulator in the phosphatidylinositol 3-kinase (PI3K)/protein kinase $\mathrm{B}$ (AKT) pathway, which has been proven to be a key upstream signaling pathway of EMT [42]. In addition, the activation of PI3K/mTOR signaling pathway has been proven to be related with HBx-induced AFP expression and subsequently promotes malignant transformation in liver cells [38]. Hence, regulation of PI3K/AKT signaling pathway may be the possible molecular mechanism that mediate AFP-induced malignant progression of liver cancer, such as tumorigenesis, growth, migration and invasion. We will investigate it in our further research.

A major limitation of our study is that the influence factor of HCC prognosis is variable, such as the AlbuminBilirubin (ALBI) score [43], tumor differentiation [44], race, pathogenic factors, and so on. Many other subclassifications of BCLC B and C stages have been proposed recent years. If possible, these factors are essential to be included in the staging model. Additionally, the clinical utility of our recommendation is still looking forward to be validated via prospective randomized studies.

In conclusion, the management of HCC is still a great challenge for clinicians. AFP, an independent prognostic factor, can be incorporated into the BCLC staging system to modify the recommended treatment of patients with stage C. Further study is needed to prospectively determine the clinical utility of this modified BCLC staging system.

\section{MATERIALS AND METHODS}

\section{Data collection and patient selection}

This study was based on public data from the SEER database; we obtained permission to access research data files with the reference number 13895-Nov2014. Given that these data are deidentified and ethics approval is waived, the study did not require informed consent, and 
was approved by the Review Board of Nanjing Medical University (Nanjing, China).

The SEER Cancer Statistics Review (http://seer. cancer.gov/data/citation.html), which is available for studies of cancer-based epidemiology and survival analysis, is published annually by the Data Analysis and Interpretation Branch of the National Cancer Institute (Bethesda, MD, USA). The SEER database includes approximately $26 \%$ of the population in the USA. Using SEER*Stat, an online access program provided by the SEER program, We extracted data from January 1, 2004, through December 31, 2008, using the National Cancer Institute's SEER*Stat software (http://seer.cancer.gov/seerstat) (Version 8.2.1).

All patients were pathological diagnosed as liver cancer based on International Classification of Diseases for Oncology, Third Edition (ICD-O-3), morphological codes (C22.0 and C22.1). Only patients with available pretreatment serum AFP level information were included. Furthermore, we included data pertaining to age; sex (male and nonpregnant female); race; histological type; TNM stage; causespecific death classification; end calculated vital status; overall survival (OS); disease-specific survival (DSS); and use of surgical resection. All AFP level information were coded as "test not done", "positive/elevated", "negative/ normal; within normal limits", "borderline; undetermined whether positive or negative", "ordered, but results not in chart" or "unknown or no information". Patients were excluded if they had no conclusive evaluation of pretreatment serum AFP level. We designated stage A0 for patients with a serum AFP level coded as "negative/normal; within normal limits" (AFP 0-15 ng/mL) and A1 for those coded as "positive/elevated" (AFP > $15 \mathrm{ng} / \mathrm{mL}$ ). All survival estimates were based on data from the SEER database. All patients were staged according to the 6th AJCC Cancer Staging Handbook [39]. Further details about the data were obtained according to the SEER Data Management System User Manual (http://seer.cancer.gov). Death was treated as events. Accordingly, alive or deaths from other causes were treated as censored observation. The primary endpoint of the study is DSS, which was calculated from the date of diagnosis to the date of disease-specific death.

\section{Statistical analyses}

The overall survival (OS) and disease-specific survival (DSS) (ie, liver cancer) curves of all stage groups were generated using standard Kaplan-Meier estimates, respectively. Differences among the curves were analyzed by log-rank test in a pairwise fashion. Univariate and multivariate Cox regression models were built to obtain hazard ratios (HRs) of risk factors for survival outcomes. We used two novel covariates (NCs), which are combination of $\mathrm{T} / \mathrm{N}$ and AFP stage to study the interaction of these covariates on prognosis. All statistical analyses were conducted using SPSS statistical software, version 19 (SPSS Inc., Chicago, IL, USA). $P<0.05$ were considered statistically significant.

\section{ACKNOWLEDGMENTS AND FUNDING}

This research was supported by grants from the JiangSu Clinical medicine Science and Technology Special Fund (No:BL2014091, http://www.jstd.gov.cn/).

\section{CONFLICTS OF INTERESTS}

The authors declare that they have no competing interests.

\section{REFERENCES}

1. Ikai I, Itai Y, Okita K, Omata M, Kojiro M, Kobayashi K, Nakanuma Y, Futagawa S, Makuuchi M, Yamaoka Y. Report of the 15th follow-up survey of primary liver cancer. Hepatology research. 2004; 28:21-29.

2. Mokdad AA, Singal AG, Yopp AC. JAMA PATIENT PAGE. Treatment of Liver Cancer. Jama. 2016; 315:100. doi: 10.1001/jama.2015.15431.

3. Kudo M, Chung H, Osaki Y. Prognostic staging system for hepatocellular carcinoma (CLIP score): its value and limitations, and a proposal for a new staging system, the Japan Integrated Staging Score (JIS score). Journal of Gastroenterology. 2003; 38:207-215.

4. A new prognostic system for hepatocellular carcinoma: a retrospective study of 435 patients: the Cancer of the Liver Italian Program (CLIP) investigators. Hepatology. 1998; 28:751-755.

5. Llovet JM, Bru C, Bruix J. Prognosis of hepatocellular carcinoma: the BCLC staging classification. Seminars in liver disease. 1999; 19:329-338.

6. Kudo M, Chung H, Osaki Y. Prognostic staging system for hepatocellular carcinoma (CLIP score): its value and limitations, and a proposal for a new staging system, the Japan Integrated Staging Score (JIS score). Journal of gastroenterology. 2003; 38:207-215.

7. Yau T, Tang VY, Yao TJ, Fan ST, Lo CM, Poon RT. Development of Hong Kong Liver Cancer staging system with treatment stratification for patients with hepatocellular carcinoma. Gastroenterology. 2014; 146:1691-1700 e1693. doi: 10.1053/j.gastro.2014.02.032.

8. Kim KM, Sinn DH, Jung SH, Gwak GY, Paik YH, Choi MS, Lee JH, Koh KC, Paik SW. The recommended treatment algorithms of the BCLC and HKLC staging systems: does following these always improve survival rates for HCC patients? Liver international. 2016. doi: 10.1111/liv.13107.

9. Song PP, Xia JF, Inagaki Y, Hasegawa K, Sakamoto Y, Kokudo N, Tang W. Controversies regarding and perspectives on clinical utility of biomarkers in hepatocellular carcinoma. World journal of gastroenterology. 2016; 22:262-274. doi: 10.3748/wjg.v22.i1.262.

10. Giannini EG, Marenco S, Borgonovo G, Savarino V, Farinati F, Del Poggio P, Rapaccini GL, Anna Di Nolfo M, 
Benvegnu L, Zoli M, Borzio F, Caturelli E, Chiaramonte M, et al. Alpha-fetoprotein has no prognostic role in small hepatocellular carcinoma identified during surveillance in compensated cirrhosis. Hepatology. 2012; 56:1371-1379. doi: 10.1002/hep.25814.

11. Yao M, Zhao J, Lu F. Alpha-fetoprotein still is a valuable diagnostic and prognosis predicting biomarker in hepatitis B virus infection-related hepatocellular carcinoma. Oncotarget. 2016; 7:3702-3708. doi: 10.18632/ oncotarget.6913.

12. Chan SL, Chan AT, Yeo W. Role of alpha-fetoprotein in hepatocellular carcinoma: prognostication, treatment monitoring or both? Future oncology. 2009; 5:889-899. doi: 10.2217/fon.09.64

13. Ishikawa K, Sasaki A, Haraguchi N, Yoshikawa Y, Mori M. A case of an alpha-fetoprotein-producing intrahepatic cholangiocarcinoma suggests probable cancer stem cell origin. The oncologist. 2007; 12:320-324.

14. Nehls O, Gregor M, Klump B. Serum and bile markers for cholangiocarcinoma. Seminars in liver disease. 2004; 24:139-154.

15. Zhu AX, Park JO, Ryoo BY, Yen CJ, Poon R, Pastorelli D, Blanc JF, Chung HC, Baron AD, Pfiffer TE, Okusaka T, Kubackova K, Trojan J, et al. Ramucirumab versus placebo as second-line treatment in patients with advanced hepatocellular carcinoma following first-line therapy with sorafenib (REACH): a randomised, double-blind, multicentre, phase 3 trial. The Lancet Oncology. 2015; 16:859-870. doi: 10.1016/S1470-204500050-9.

16. Yaprak O, Akyildiz M, Dayangac M, Demirbas BT, Guler N, Dogusoy GB, Yuzer Y, Tokat Y. AFP level and histologic differentiation predict the survival of patients with liver transplantation for hepatocellular carcinoma. Hepatobiliary \& pancreatic diseases international. 2012; 11:256-261.

17. Sotiropoulos GC, Molmenti EP, Lang H. Liver transplantation for hepatocellular carcinoma in the MELD era: leading roles of MELD score, AFP level, and recipient age as predictors of survival. Digestive diseases and sciences. 2009; 54:917. doi: 10.1007/s10620-008-0680-5.

18. Marubashi S, Dono K, Nagano H, Sugita Y, Asaoka T, Hama N, Miyamoto A, Takeda Y, Umeshita K, Monden M. Detection of AFP mRNA-expressing cells in the peripheral blood for prediction of HCC recurrence after living donor liver transplantation. Transplant international. 2007; 20:576-582.

19. Cuccurullo V, Mansi L. AJCC Cancer Staging Handbook: from the AJCC Cancer Staging Manual (7th edition). European Journal of Nuclear Medicine and Molecular Imaging. 2010; 38:408-408.

20. Kudo M, Arizumi T, Ueshima K, Sakurai T, Kitano M, Nishida N. Subclassification of BCLC B Stage Hepatocellular Carcinoma and Treatment Strategies: Proposal of Modified Bolondi's Subclassification (Kinki
Criteria). Digestive diseases. 2015; 33:751-758. doi: 10.1159/000439290.

21. Wang Y-Y, Zhong J-H, Qin H-G, Li L-Q. Comment on: Surgical resection versus transarterial chemoembolization for BCLC stage C hepatocellular carcinoma. Journal of Surgical Oncology. 2015; 112:907-908. doi: 10.1002/jso.24066.

22. Sinn DH, Cho JY, Gwak GY, Paik YH, Choi MS, Lee JH, Koh KC, Paik SW, Yoo BC. Different survival of Barcelona clinic liver cancer stage $\mathrm{C}$ hepatocellular carcinoma patients by the extent of portal vein invasion and the type of extrahepatic spread. PloS one. 2015; 10:e0124434. doi: 10.1371/journal.pone.0124434.

23. Roayaie S, Jibara G, Tabrizian P, Park JW, Yang J, Yan L, Schwartz M, Han G, Izzo F, Chen M, Blanc JF, Johnson P, Kudo M, et al. The role of hepatic resection in the treatment of hepatocellular cancer. Hepatology. 2015; 62:440-451. doi: 10.1002/hep.27745.

24. Bolondi L, Burroughs A, Dufour JF, Galle PR, Mazzaferro V, Piscaglia F, Raoul JL, Sangro B. Heterogeneity of patients with intermediate (BCLC B) Hepatocellular Carcinoma: proposal for a subclassification to facilitate treatment decisions. Seminars in liver disease. 2012; 32:348-359. doi: 10.1055/s-0032-1329906.

25. Jung YK, Jung CH, Seo YS, Kim JH, Kim TH, Yoo YJ, Kang SH, Yim SY, Suh SJ, An H, Yim HJ, Yeon JE, Byun KS, et al. BCLC stage B is a better designation for single large hepatocellular carcinoma than BCLC stage A. Journal of gastroenterology and hepatology. 2016; 31:467474. doi: 10.1111/jgh.13152.

26. Liu PH, Hsia CY, Lee YH, Hsu CY, Huang YH, Su CW, Lee RC, Lin HC, Huo TI. Surgical resection versus transarterial chemoembolization for BCLC stage C hepatocellular carcinoma. J Surg Oncol. 2015; 111:404-409. doi: 10.1002/jso.23854.

27. Zarrinpar A, Kaldas F, Busuttil RW. Liver transplantation for hepatocellular carcinoma: an update. Hepatobiliary \& pancreatic diseases international. 2011; 10:234-242.

28. Heckman JT, Devera MB, Marsh JW, Fontes P, Amesur NB, Holloway SE, Nalesnik M, Geller DA, Steel JL, Gamblin TC. Bridging locoregional therapy for hepatocellular carcinoma prior to liver transplantation. Annals of surgical oncology. 2008; 15:3169-3177. doi: 10.1245/s10434-008-0071-3.

29. Schraiber Ldos S, de Mattos AA, Zanotelli ML, Cantisani GP, Brandao AB, Marroni CA, Kiss G, Ernani L, Marcon Pdos S. Alpha-fetoprotein Level Predicts Recurrence After Transplantation in Hepatocellular Carcinoma. Medicine. 2016; 95:e2478. doi: 10.1097/MD< 0.0010000000002478 .

30. Geschwind JF, Salem R, Carr BI, Soulen MC, Thurston KG, Goin KA, Van Buskirk M, Roberts CA, Goin JE. Yttrium-90 microspheres for the treatment of hepatocellular carcinoma. Gastroenterology. 2004; 127:S194-205.

31. Kulik LM, Carr BI, Mulcahy MF, Lewandowski RJ, Atassi B, Ryu RK, Sato KT, Benson A, 3rd, Nemcek AA, Jr., 
Gates VL, Abecassis M, et al. Safety and efficacy of 90Y radiotherapy for hepatocellular carcinoma with and without portal vein thrombosis. Hepatology. 2008; 47:71-81.

32. Hilgard P, Hamami M, Fouly AE, Scherag A, Muller S, Ertle J, Heusner T, Cicinnati VR, Paul A, Bockisch A, Gerken G, Antoch G. Radioembolization with yttrium-90 glass microspheres in hepatocellular carcinoma: European experience on safety and long-term survival. Hepatology. 2010; 52:1741-1749. doi: 10.1002/hep.23944.

33. Palmer DH. Sorafenib in advanced hepatocellular carcinoma. The New England journal of medicine. 2008; 359:2498; author reply 2498-2499.

34. Saab S, McTigue M, Finn RS, Busuttil RW. Sorafenib as adjuvant therapy for high-risk hepatocellular carcinoma in liver transplant recipients: feasibility and efficacy. Experimental and clinical transplantation. 2010; 8:307-313.

35. Zahavi T, Lanton T, Divon MS, Salmon A, Peretz T, Galun E, Axelrod JH, Sonnenblick A. Sorafenib treatment during partial hepatectomy reduces tumorgenesis in an inflammation-associated liver cancer model. Oncotarget. 2016; 7:4860-4870. doi: 10.18632/oncotarget.6638.

36. Bruix J, Sherman M, American Association for the Study of Liver D. Management of hepatocellular carcinoma: an update. Hepatology. 2011; 53:1020-1022. doi: 10.1002/ hep. 24199.

37. Kim JY, Lee HY, Park KK, Choi YK, Nam JS, Hong IS. CWP232228 targets liver cancer stem cells through Wnt/ betacatenin signaling: a novel therapeutic approach for liver cancer treatment. Oncotarget. 2016; 7:20395-409. doi: 10.18632/oncotarget.7954.

38. Zhu M, Guo J, Li W, Lu Y, Fu S, Xie X, Xia H, Dong X, Chen Y, Quan M, Zheng S, Xie K, Li M. Hepatitis B virus $\mathrm{X}$ protein induces expression of alpha-fetoprotein and activates PI3K/mTOR signaling pathway in liver cells. Oncotarget. 2015; 6:12196-12208. doi: 10.18632/ oncotarget.2906.

39. Li M, Zhu M, Li W, Lu Y, Xie X, Wu Y, Zheng S. Alphafetoprotein receptor as an early indicator of HBx-driven hepatocarcinogenesis and its applications in tracing cancer cell metastasis. Cancer Letter. 2013; 330:170-180. doi: 10.1016/j.canlet.2012.11.042.

40. Zhu M, Li W, Lu Y, Dong X, Chen Y, Lin B, Xie X, Guo J, Li M. Alpha fetoprotein antagonizes apoptosis induced by paclitaxel in hepatoma cells in vitro. Science Reports. 2016; 6:26472. doi: 10.1038/srep26472.

41. Lu Y, Zhu M, Li W, Lin B, Dong X, Chen Y, Xie X, Guo J, Li M. Alpha fetoprotein plays a critical role in promoting metastasis of hepatocellular carcinoma cells. Journal of Cellular and Molecular Medicine. 2016 Mar;20:549-558. doi: $10.1111 / \mathrm{jcmm} .12745$.

42. Li M, Li H, Li C, Wang S, Jiang W, Liu Z, Zhou S, Liu X, McNutt MA, Li G. Alpha-fetoprotein: a new member of intracellular signal molecules in regulation of the PI3K/ AKT signaling in human hepatoma cell lines. International Journal of Cancer. 2011; 128:524-532. doi: 10.1002/ ijc. 25373 .

43. Chan AW, Kumada T, Toyoda H, Tada T, Chong CC, Mo FK, Yeo W, Johnson PJ, Lai PB, Chan AT, To KF, Chan SL. Integration of albumin-bilirubin (ALBI) score into Barcelona clinic liver cancer (BCLC) system for hepatocellular carcinoma. Journal of gastroenterology and hepatology. 2016. doi: 10.1111/jgh.13291.

44. Wang YY, Huang S, Zhong JH, Ke Y, Guo Z, Liu JQ, Ma L, Li H, Ou BN, Li LQ. Impact of diabetes mellitus on the prognosis of patients with hepatocellular carcinoma after curative hepatectomy. PloS one. 2014; 9:e113858. doi: 10.1371/journal.pone.0113858.

45. Lee SD, Park SJ, Han SS, Kim SH, Kim YK, Lee SA, Ko YH, Hong EK. Clinicopathological features and prognosis of combined hepatocellular carcinoma and cholangiocarcinoma after surgery. Hepatobiliary \& pancreatic diseases international. 2014; 13:594-601. 